\title{
Mapping Soil Salinity Using a Similarity-based Prediction Approach: A Case Study in Huanghe River Delta, China
}

\author{
YANG Lin ${ }^{1}$, HUANG Chong ${ }^{1}$, LIU Gaohuan ${ }^{1}$, LIU Jing ${ }^{2}$, ZHU A-Xing ${ }^{1,2,3}$ \\ (1. State Key Laboratory of Resources and Environment Information System, Institute of Geographical Sciences and Natural Resources \\ Research, Chinese Academy of Sciences, Beijing 100101, China; 2. Department of Geography, University of Wisconsin-Madison, \\ Madison WI 53706, USA; 3. Jiangsu Center for Collaborative Innovation in Geographical Information Resource Development and Ap- \\ plication and School of Geography, Nanjing Normal University, Nanjing 210023, China)
}

\begin{abstract}
Spatial distribution of soil salinity can be estimated based on its environmental factors because soil salinity is strongly affected and indicated by environmental factors. Different with other properties such as soil texture, soil salinity varies with short-term time. Thus, how to choose powerful environmental predictors is especially important for soil salinity. This paper presents a similarity-based prediction approach to map soil salinity and detects powerful environmental predictors for the Huanghe (Yellow) River Delta area in China. The similarity-based approach predicts the soil salinities of unsampled locations based on the environmental similarity between unsampled and sampled locations. A dataset of 92 points with salt data at depth of 30-40 cm was divided into two subsets for prediction and validation. Topographical parameters, soil textures, distances to irrigation channels and to the coastline, land surface temperature from Moderate Resolution Imaging Spectroradiometer (MODIS), Normalized Difference Vegetation Indices (NDVIs) and land surface reflectance data from Landsat Thematic Mapper (TM) imagery were generated. The similarity-based prediction approach was applied on several combinations of different environmental factors. Based on three evaluation indices including the correlation coefficient (CC) between observed and predicted values, the mean absolute error and the root mean squared error we found that elevation, distance to irrigation channels, soil texture, night land surface temperature, NDVI, and land surface reflectance Band 5 are the optimal combination for mapping soil salinity at the 30-40 cm depth in the study area (with a CC value of 0.69 and a root mean squared error value of 0.38 ). Our results indicated that the similarity-based prediction approach could be a vital alternative to other methods for mapping soil salinity, especially for area with limited observation data and could be used to monitor soil salinity distributions in the future. Keywords: soil salinization; similarity-based prediction approach; digital soil mapping; Huanghe (Yellow) River Delta; environmental factor
\end{abstract}

Citation: Yang Lin, Huang Chong, Liu Gaohuan, Liu Jing, Zhu A-Xing, 2015. Mapping soil salinity using a similarity-based prediction approach: a case study in Huanghe River Delta, China. Chinese Geographical Science, 25(3): 283-294. doi: 10.1007/s11769-0150740-7

\section{Introduction}

Soil salinization, which occurs through natural or humaninduced processes that result in the accumulation of dissolved salts in soils, is one of the most widespread soil degradation processes on the Earth. According to the Land and Plant Nutrition Management Service, Food and Agriculture Organization of the United Nations (FAO), over $6 \%$ of the global land is saline or sodic. On average, twenty percent of the world's irrigated lands

Received date: 2014-06-03; accepted date: 2014-08-29

Foundation item: Under the auspices of Special Fund for Ocean Public Welfare Profession Scientific Research (No. 201105020), National Natural Science Foundation of China (No. 41471178, 41023010, 41431177), National Key Technology Innovation Project for Water Pollution Control and Remediation (No. 2013ZX07103006)

Corresponding author: HUANG Chong. E-mail: huangch@1reis.ac.cn

(C) Science Press, Northeast Institute of Geography and Agroecology, CAS and Springer-Verlag Berlin Heidelberg 2015 
are affected by salts (Ghassemi et al., 1995). Under increasing population pressure in the future, more drylands will be cultivated with irrigation, which may lead to increased secondary salinization. A spatial representation of soil salinity is essential to facilitate regional planning and agricultural management and to provide decision makers with a reference tool. Therefore, there is a growing interest in identifying effective tools for mapping the spatial distribution of soil salinity (Metternicht and Zinck, 2003; Yao and Yang, 2010).

Abundant remote sensing data from various sensors (e.g., aerial photographs, satellite and airborne multispectral sensors, hyperspectral sensors and electromagnetic induction instruments) have been used to map salt-affected soils (Abbas et al., 2013), because the surface features of salt-affected soils can be detected using those data. Metternicht and Zinck (2003) and Farifteh et al. (2006) reviewed data from different sources and approaches used for the remote identification and mapping of salt-affected areas. However, there are several limitations to remote sensing-based approaches. For example, it is usually difficult to distinguish between low-saline and nonsaline soils. Salt detection is also influenced by the presence of vegetation and other surface features, which might contribute to spectral confusion with regard to the salt reflectance properties (Metternicht and Zinck, 2003). Additionally, the direct and precise estimation of salt quantities from satellite remote sensing data is rather difficult (Mougenot et al., 1993). According to Metternicht and Zinck (2003), the best monitoring results are obtained when integrating remote sensing data with field and laboratory data.

Soil salinization is a product of complex interactions between soil salinity and environmental factors such as soil parent materials, soil texture and terrain conditions; thus, the soil salinity of a location is affected by and can be estimated based on its environmental factors. Numerous studies have been conducted to understand the relationships between soil salinity and environmental factors, to explore powerful predictors or indicators of soil salinity (Scull et al., 2005; Akramkhanov et al., 2011; Jafari et al., 2012) and to map the spatial variations of soil salinity based on field observations (Triantafilis et al., 2001; Yao and Yang, 2010; TaghizadehMehrjardi et al., 2014). Statistical or geostatistical methods are commonly utilized, such as multiple linear regression, regression tree and kriging approaches. For methods such as multiple linear regression, a fixed function or model is usually simulated for the entire study area. However, relationships between soil salinity and environmental factors are not always universal for all locations in the entire area. Therefore, this type of methods is limited when using the same function to model soil salinity variations. For geostatistical methods, such as cokriging or regression kriging, soil salinity variation does not often satisfy the basic stationary assumptions of Kriging methods due to its complex variations. Additionally, an adequate number of point-pairs must be available for the construction of a variogram for kriging. Webster and Oliver (2001) suggest at least 50 and preferably 300 points for variogram estimation, and Hengl et al. (2007) recommend using regression kriging only for datasets with more than 50 total observations and at least 10 observations per predictor to prevent over-fitting. For area with limited observation data, kriging methods are limited.

Based on the relationships between soil salinity and environmental factors, the more similar the environmental conditions are between two locations, the more similar the soil salt values are likely to be. Thus, the similarity of environmental conditions between locations can be used to predict soil salinities. In this study, a similarity-based approach (Zhu, 1997; Shi et al., 2004; Liu, 2010) was used to simulate the spatial variation of soil salinity in the Huanghe (Yellow) River Delta based on both field observation data and environmental data. The similarity-based soil mapping method predicts the soil properties of unsampled locations based on the environmental similarity between unsampled locations and sampled locations. This approach was previously applied successfully in the mapping of soil series, soil texture, soil profile depths and soil organic matter content (Shi et al., 2004; Liu, 2010). In the research of Shi et al. (2004), a soil series map was predicted with an accuracy of $86 \%$, and the derived maps of depth to $C$ horizon and A horizon texture were more accurate than the published conventional soil survey maps with the mean absolute error (MAE) and the root mean square error (RMSE) as validation indices. Liu (2010) obtained a soil organic matter map of the top soil in Ili of Xinjiang, China using the similarity-based approach, and a comparison with the soil organic matter map using a traditional linkage method showed that the map based on the similarity-based approach was much accurate. Different with those soil properties such as soil texture 
and soil organic matter content, soil salinity usually varies with short-term time and is easily influenced by conditions like weather, thus can be considered as a dynamic soil property. For soil salinity, how to choose powerful environmental predictors is especially important. Thus, the objectives of this paper are as follows: to detect useful environmental variables for predicting soil salinity variations in the Huanghe River Delta area, and to test the predictive power of the similarity-based approach for mapping soil salinity. The procedure employed consisted of four stages: 1) generating environmental factors that could influence or indicate soil salinity in the Huanghe River Delta area; 2) conducting correlation analyses between the soil salinities and the environmental factors; 3) applying the similarity-based prediction approach to different combinations of environmental factors and evaluating the predicted soil salinity maps; 4) choosing the optimal environmental combinations and producing the soil salinity maps.

\section{Materials and Methods}

\subsection{Study area}

The study area is the modern Huanghe River Delta area $\left(37^{\circ} 24^{\prime}-38^{\circ} 06^{\prime} \mathrm{N}, 118^{\circ} 14^{\prime}-119^{\circ} 11^{\prime} \mathrm{E}\right)$ formed since the avulsion in 1855, which is located in Dongying City, Shandong Province, China, on the southern shore of the Bohai Sea (Fig. 1). The delta has been formed by the sediments deposited by the Huanghe River with an area of $5400 \mathrm{~km}^{2}$. Soil salinization is a severe problem in this area due to the presence of a shallow water table and seawater intrusion. Saline land covers more than $70 \%$ of the total area. The area has a temperate continental monsoon climate with rainy summers. The annual average precipitation is approximately $530-630 \mathrm{~mm}$, and the annual average evaporation is $1900-2400 \mathrm{~mm}$.

Among the large river deltas in the world, the Huanghe River Delta is one of the most active regions of land-ocean interaction (Cui et al., 2009; Li et al., 2009). The delta is traversed by the Huanghe River, which controls heavy sediment discharge (Xie et al., 2011), and has a fan shape resulting from periodic shifts in the location of the channel mouth. The soil structure and texture of the sedimentary soil formed in the Huanghe River Delta influence the infiltration of water and the salinization process. The landforms in this area are controlled mostly by the evolution of the Huanghe
River (Xu, 1997). Although this area has a very gentle terrain with low relief from 0 to $18.6 \mathrm{~m}$ above sea level (Fig. 1), micro-topographic features vary over the area, including high ground formed because of the river, flat ground, depressions, overflow land and tidal flats. The differences in the micro-topographic features not only determine the types of soil textures but also influence the subsurface water status, the degree of surface evaporation and the salt content of the soil (Song et al., 2013). The highly mineralized underground water and high groundwater levels with an average depth of $1.14 \mathrm{~m}$ (Fan et al., 2012) in this area also cause soil salinization.

The natural vegetation in the study area is composed of sparse halophytic plant communities dominated by grass and shrub species. In recent decades, the Huanghe River Delta has experienced extensive agricultural and industrial development (Zhou et al., 2007; Wang et al., 2011; Zhang et al., 2011). Large portions of the grassland and wilderness have been cultivated with salttolerant crops and grasses, such as cotton, maize, clover and Chinese date, and the wide foreshore areas have been exploited as extensive shrimp ponds and salt pans (Zhou et al., 2007). The intensive human activities have led to secondary salinization and pose a threat to the food production and the local environment ( $\mathrm{Ye}$ et al., 2004; Fang et al., 2005).

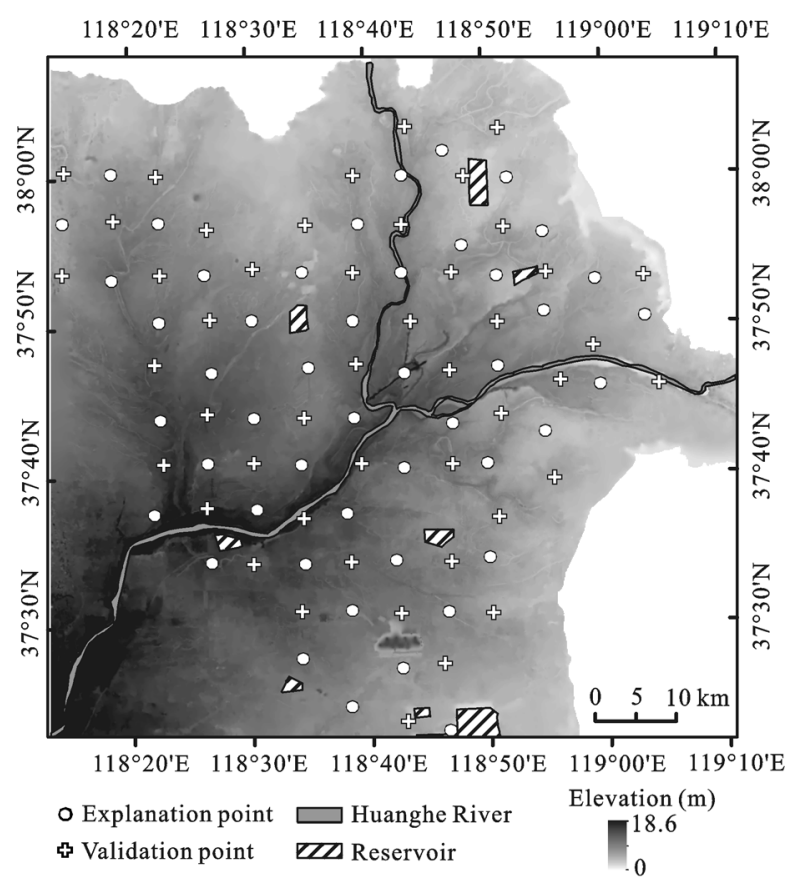

Fig. 1 Digital elevation model (DEM) and sampling points of study area 


\subsection{Data and processing}

\subsubsection{Soil sampling data}

Ninety-two sampling points were taken using a systematic sampling strategy from October 8th to 27th, 2003 (Fig. 1). A $6 \mathrm{~km}$ by $6 \mathrm{~km}$ grid arrangement was originally designed. Due to limitation of accessibility, some points that were located in inaccessible areas were replaced by accessible points that were close to original designed points. The locations of the points were determined with a GPS handset with a positional error of less than $10 \mathrm{~m}$. Soil samples at the depth of $30-40 \mathrm{~cm}$ were collected and tested for the method in this case study (notice that this method can be applied at any soil depth). Total salt contents (\%) of samples were calculated by summing the eight ions analyzed using $1 / 5 \mathrm{di}-$ luted extracts method. The dataset was divided into two parts: 47 points for modeling and 45 for validation, both in diamond distributions. The total salt values for the $30-40 \mathrm{~cm}$ depth of the sampling set ranged from $0.04 \%$ to $2.04 \%$, with an average value of $0.53 \%$ and a standard deviation of $0.46 \%$.

\subsubsection{Environmental data}

The environmental factors related to soil salinity can be categorized into two types: influencing environmental factors and indicative environmental factors. The first type includes factors that influence or determine the spatial distribution of soil salinity, such as soil parent materials, soil texture, precipitation, transpiration, terrain parameters and distance to the coast or irrigation channels. The other type of environmental variables can indicate the spatial distribution of soil salinity, including land surface reflectance data (such as spectral data from remote sensing) and vegetation variables.

Based on both the understanding of the interactions between soil salinity and the environmental factors in the study area and the availability of such environmental factors, six types of environmental data, and 23 variables were selected (Table 1).

A 30-m resolution Digital Elevation Model (DEM) was derived from a 1:10000 scale topographic map provided by Chinese Bureau of Surveying and Mapping in 1987. Four terrain variables were derived from the DEM: slope (Slp), profile curvature (Pcuv), planform curvature (Fcuv) and the topographic wetness index (TWI) (Fig. 2). The first three variables were computed using the terrain analysis software 3D Mapper (www. terrainanalytics.com). The TWI was calculated using the following equation (Quinn et al., 1995):

$$
T W I=\ln \left(\frac{\alpha}{\tan \beta}\right)
$$

where $\alpha$ is the cumulative upslope area draining through a point (per unit contour length) and $\beta$ is the slope gradient at the point. Because of the gentle terrain in the

Table 1 Environmental variables of soil salinity selected in this study

\begin{tabular}{|c|c|c|}
\hline Type of environmental factor & Environmental factor & Variable \\
\hline \multirow{12}{*}{ Influencing environmental factor } & \multirow{8}{*}{ Terrain attribute } & Elevation (Ele) \\
\hline & & Slope derived from original DEM (Slp) \\
\hline & & Slope derived from 10-fold DEM (Slp10) \\
\hline & & Profile curvature derived from original DEM (Pcuv) \\
\hline & & Profile curvature derived from 10-fold DEM (Pcuv10) \\
\hline & & Planform curvature derived from original DEM (Fcuv) \\
\hline & & Planform curvature derived from 10-fold DEM (Fcuv10) \\
\hline & & Topographic wetness index (TWI) \\
\hline & \multirow{2}{*}{ Distance index } & Distance to coastline (Dist_cl) \\
\hline & & Distance to irrigation channel (Dist_ic) \\
\hline & Soil texture & Soil texture category (ST) \\
\hline & Land surface temperature & $\begin{array}{l}\text { Average day }\left(\mathrm{T}_{-} \text {avg_d}\right) \text { and night }\left(\mathrm{T}_{-} \text {avg_n}\right) \text { land surface temperature during sampling } \\
\text { period derived from MODIS } 8 \text {-day temperature products }\end{array}$ \\
\hline \multirow{2}{*}{ Indicative environmental factor } & Land surface reflectance & $\begin{array}{l}\text { Landsat } 5 \text { Thematic Mapper (TM) surface reflectance Climate Data Record (CDR), } \\
\text { Band 1, 2, 3, 4, 5, } 7 \text { (Lsr_b1, Lsr_b2, ...,Lsr_b7) }\end{array}$ \\
\hline & Vegetation index & $\begin{array}{l}\text { Normalized Difference Vegetation Index (NDVI) from Landsat } 5 \text { TM (NDVI } 030127, \\
\text { NDVI 030212, NDVI 030924, NDVI 031026) }\end{array}$ \\
\hline
\end{tabular}


study area, a multiple-flow-direction strategy MFD-md (Qin et al., 2007) was used to calculate the upslope drainage area using the software SimDTA 1.0 (Qin et al., 2009).

A 10-fold DEM was generated by multiplying the original elevation by 10 , because the original DEM and its derived attributes may have difficulty in depicting the micro-topographic features in this area. Three variables were derived from the 10-fold DEM to determine whether these variables could more effectively depict the micro-topographic features: slope (Slp10), profile curvature (Pcuv10) and planform curvature (Fcuv10). The two distance indices, distance to irrigation channels (Dist_ic) and distance to coastline (Dist_cl), were generated with a cell size of 30-m using ArcGIS 10.0 (ESRI Inc., Redlands, CA, USA) based on the irrigation channels and coastline data (Figs. $2 \mathrm{~h}$ and $2 \mathrm{i}$ ). The soil texture category map was produced by the Land Resource Investigation Bureau of Dongying City based on the 1 : 200000 scale soil type map of this area. There are five categories of soil texture in the area: sandy loam distributed along the coast, the Huanghe River channel and old
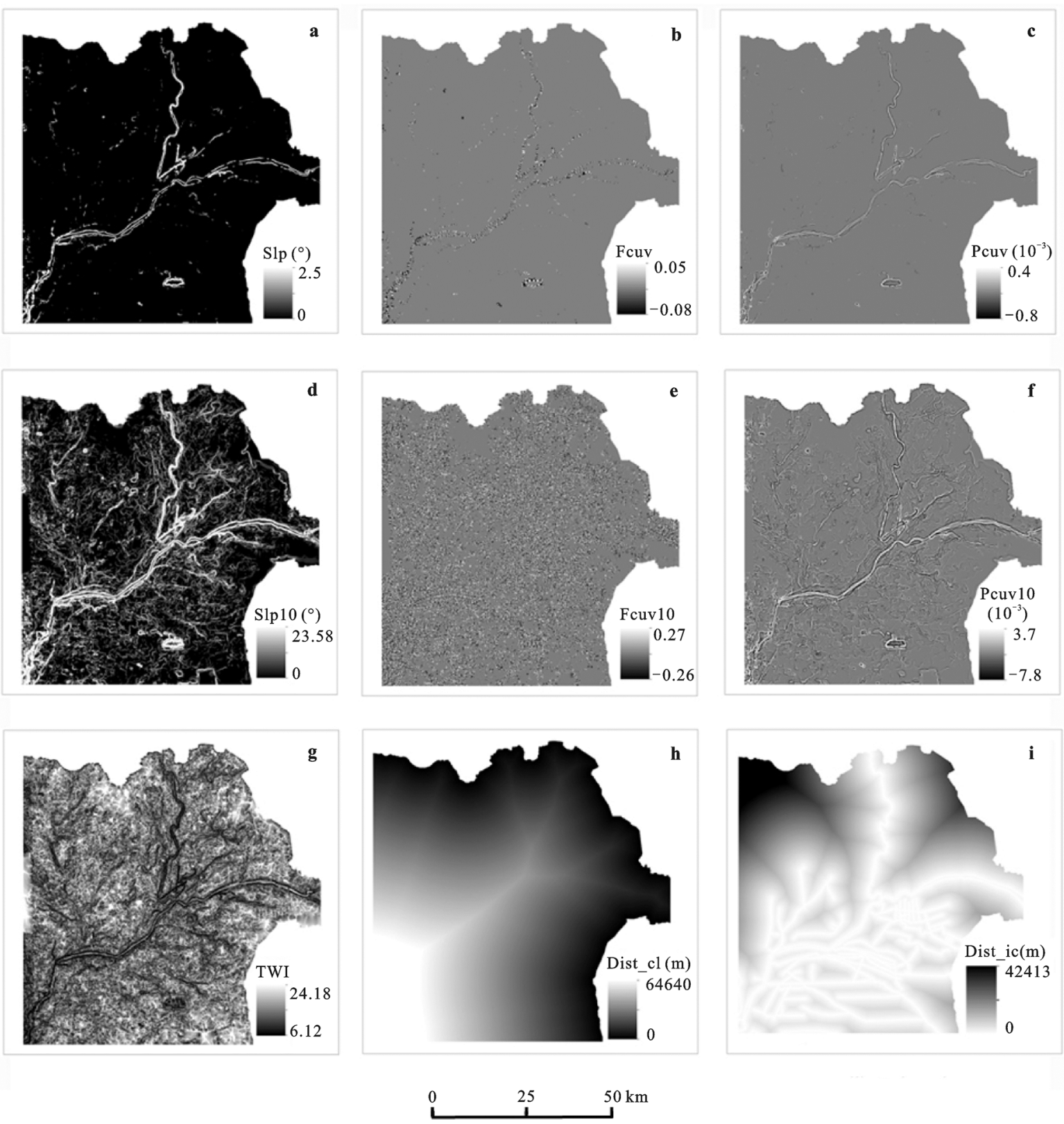

Fig. 2 Terrain and distance variables of Huanghe River Delta area. Meanings of all the abbreviations mentioned in the figure are listed in Table 1 
river channels; clayey loam; silty clay; clay in the southern and northeastern areas; and sandy clay loam in the middle and northern areas (Fig. 3). Transpiration is one important factor influencing soil salinity, but the data are usually difficult to obtain. In this study, we used land surface temperature, of which the data is easy to obtain through remote sensing techniques, with the purpose to indicate soil and vegetation transpiration to some extent. MOD11A2 8-day day and night land surface temperature data at three dates (October 8,16 , and 24, 2003) (http://ladsweb.nascom.nasa.gov/data/search. html.) during the sampling period were used. A simple average method is used to generate the average day (T_avg_d) and night (T_avg_n) land surface temperature during the sampling period. The original resolution of these temperature data is $1 \mathrm{~km}$ and resampled to $30 \mathrm{~m}$.

Two types of indicative environmental variables were examined in this study. The first type is land surface reflectance data, which were collected from the Landsat 5 TM surface reflectance Climate Data Record (CDR) data on October 26, 2003 (which is the only available product during the sampling period) with the resolution of $30 \mathrm{~m}$, (http://earthexplorer.usgs.gov/). The other indicative environmental variable is vegetation cover data. It is reported that there is a correlation relationship between soil salinity and vegetation species in the Huanghe

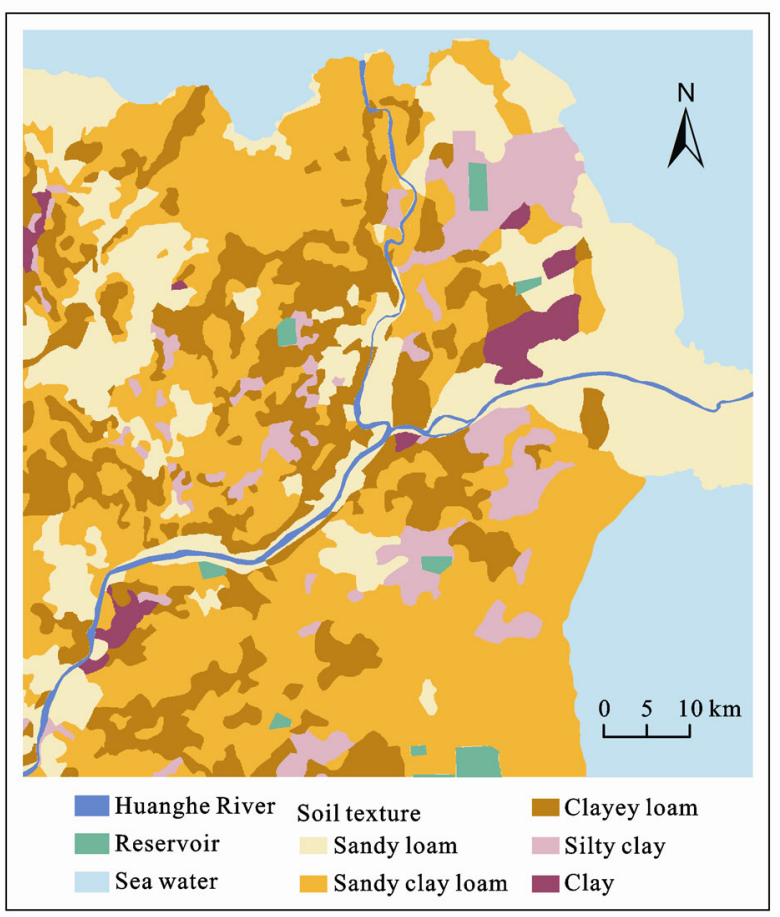

Fig. 3 Soil texture category map of Huanghe River Delta area
River Delta (Zhao et al., 2010; Ma et al., 2013). We used the Normalized Difference Vegetation Index (NDVI) as an indicator of vegetation coverage in this area. The NDVI is calculated using the following equation:

$N D V I=\frac{(N I R-R E D)}{(N I R+R E D)}$

where $N I R$ and $R E D$ stand for the spectral reflectance measurements acquired in the near-infrared and visible red bands, respectively.

To find a date for which the NDVI can adequately indicate soil salinity, we downloaded all the available NDVIs without clouds (i.e., the NDVIs for January 27, 2003; February 12, 2003; September 24, 2003; and October 26,2003$)$ from http://earthexplorer.usgs.gov/.

\subsection{Methods}

\subsubsection{Correlation analysis between soil salinity and environmental factors}

Correlation analysis was conducted to measure the correlation between soil salinity and environmental factors in SPSS Statistics 17.0 (SPSS Inc., Chicago, USA). For soil salt content $v_{k}$ in location $k$ and the environmental variable $e_{k}(k=1,2, \ldots, n$; where $n$ is the number of sampled locations), the Pearson correlation coefficient between them is defined as:

$$
r=\frac{\sum_{k=1}^{n}\left(v_{k}-\bar{v}\right)\left(e_{k}-\bar{e}\right)}{\sqrt{\sum_{k=1}^{n}\left(v_{k}-\bar{v}\right)^{2}} \sqrt{\sum_{k=1}^{n}\left(e_{k}-\bar{e}\right)^{2}}}
$$

where $\bar{v}$ and $\bar{e}$ are the means of $v_{k}$ and $e_{k}$, respectively (Rodgers and Nicewander, 1988).

\subsubsection{Similarity-based method for predicting soil sa- linity}

The similarity-based approach (Shi et al., 2004; Liu, 2010) predicts the soil salinity of an unsampled location based on its similarity with sampled locations. The similarity between a given unsampled location and sampling points can be approximated by the similarity of the environment conditions between them. The method consists of two major steps: 1) calculating environmental similarities between unsampled locations and sampling points, and 2) predicting soil salinity based on the environmental similarity. 
(1) Calculating environmental similarities between unsampled locations and sampling points

Environmental similarities between unsampled locations and sampled locations are determined based on the environmental vector of each location. This procedure is implemented on two levels represented with a generic equation (Equation (4)): 1) at the individual environmental variable level and 2) at the location level, which integrates similarities from all environmental variables into one value expressing the similarity to the given sampled location.

$S_{i j}^{k}=\stackrel{m}{P}\left(E^{v}\left(e_{i j}^{v}, e_{k}^{v}\right)\right)$

where $S_{i j}^{k}$ represents the similarity between an unsampled location $(i, j)$ and the $k$-th sampled location; $e_{i j}^{v}$ is the value of the $v$-th environmental variable at location $(i, j)$ and $e_{k}^{v}$ is the value of the $v$-th environmental variable associated with sample $k . E^{v}$ is the function that evaluates the similarity on the individual environmental variable level, and this function can be specific for the data type of the $v$-th environmental variable (Liu, 2010). If the environmental variable is nominal or ordinal, $E$ will be a Boolean function. If the environmental variable is an interval or ratio variable, the Gower similarity coefficient (Gower, 1971) was adopted in this research. The $P$-function is used to integrate the variable-level similarities into the location level. In this research, the minimum operator (Zhu and Band, 1994) was used, based on the limiting factor principle, which assumes that the limiting factor controls the development of soil salinization.

After calculating similarities to all the sampled locations, a similarity vector $S_{i j}$, in which each element is the environmental similarity between umsampled location $(i, j)$ and sampled location $k$, is generated at each location $(i, j)$ :

$S_{i j}=\left(S_{i j}^{1}, S_{i j}^{2}, \ldots, S_{i j}^{k}, \ldots, S_{i j}^{n}\right)$

(2) Predicting soil salinity based on environmental similarities

This step predicts the soil salinity values using the environmental similarities of each sampled location as weights using the SoLIM software. The specific equation is shown as Equation (6) (Liu, 2010), which assumes that the sampled location $l$ is the most similar sampled location to location $(i, j)$ with the maximum similarity of the $n$ sampling points:

$$
\begin{aligned}
& V_{i j}=S_{i j}^{l} \times V_{l}+\left(1-S_{i j}^{l}\right) \times \\
& \frac{S_{i j}^{1} \times V_{1}+S_{i j}^{2} \times V_{2}+\ldots+S_{i j}^{l-1} \times V_{l-1}+S_{i j}^{l+1} \times V_{l+1}+\ldots+S_{i j}^{n} \times V_{n}}{S_{i j}^{1}+S_{i j}^{2}+\ldots+S_{i j}^{l-1}+S_{i j}^{l+1}+\ldots+S_{i j}^{n}}
\end{aligned}
$$

where $V_{i j}$ is the predicted soil property value at location $(i, j)$ and $V_{l}$ is the soil salinity value of sampled location $l$.

\subsubsection{Evaluation indices}

The evaluation of the predicted soil salinity map was based on the validation points. Three indices were used: Pearson correlation coefficient (CC), mean absolute error (MAE) and root mean square error (RMSE), which are defined as follows:

$$
\begin{gathered}
C C=\frac{\sum_{h=1}^{o}\left(v_{h}^{\mathrm{pre}}-\overline{v^{\mathrm{pre}}}\right)\left(v_{h}^{\mathrm{obs}}-\overline{v^{\mathrm{obs}}}\right)}{\sqrt{\sum_{h=1}^{o}\left(v_{h}^{\mathrm{pre}}-\overline{v^{\mathrm{pre}}}\right)^{2}} \sqrt{\sum_{h=1}^{o}\left(v_{h}^{\mathrm{obs}}-\overline{v^{\mathrm{obs}}}\right)^{2}}} \\
M A E=\frac{1}{o} \sum_{h=1}^{o}\left|v_{h}^{\mathrm{pre}}-v_{h}^{\mathrm{obs}}\right| \\
R M S E=\sqrt{\frac{\sum_{h=1}^{o}\left(v_{h}^{\mathrm{pre}}-v_{h}^{\mathrm{obs}}\right)^{2}}{o}}
\end{gathered}
$$

where $o$ is the number of the validation locations, $v_{h}^{\text {pre }}$ is the predicted soil salinity values at location $h$, $v_{h}^{\text {obs }}$ is the observed soil salinity values at location $h$ and $\overline{v^{\text {pre }}}$ and $\overline{v^{\text {obs }}}$ are the means of $v_{h}^{\text {pre }}$ and $v_{h}^{\text {obs }}$, respectively.

\section{Results}

\subsection{Correlation relationships between soil salt and environmental factors}

The Pearson correlation coefficients between the environmental variables and total salt measurements are listed in Table 2 and Table 3. For the terrain variables, the correlation coefficient for Ele was the strongest and considerably higher than the others. This is mainly because elevation controls the groundwater level which largely influences water and soil salinity migration. 
Among the other terrain variables, Slp10 showed a stronger correlation than the others, with a coefficient of -0.18 for total salt. This finding implies that Slp10 may better represent the micro-topographic variations than Slp. The profile curvatures, planform curvatures and the TWI exhibited very weak correlations with total salt. This pattern is probably because the area is quite flat. The distance indices showed moderate correlations with total salt contents. The average night land surface temperature ( $\mathrm{T} \_$avg_n) showed a very strong positive correlation with total salt, while the average day land surface temperature ( $\left.T \_a v g \_d\right)$ showed a moderate negative correlation with total salt.

The correlations between the indicative variables and the total salt measured were very high. The correlations between the NDVIs and the total salt were generally strong, among which NDVI030924 showed the strongest correlation. A possible reason for this finding is that the harvest season is at the end of September and the growth vigor at that time may effectively represent soil salt status. Although vegetation is also vigorous in summer, plentiful rain during this season leaches salt and weakens the correlations between vegetation and the soil salt status. A possible reason why NDVI031026, which is during the sampling period, did not have the strongest correlation with soil salt is that some crops had been harvested at that time. For the land surface reflectance data, Band 5 showed a stronger correlation with total salt than the other five bands. This band is reported to be sensitive to the moisture content of vegetation and soils, which may explain the high correlation coefficient.

\subsection{Soil salt mapping and evaluations}

To investigate the performance of environmental variables in total salt mapping, several combinations of different environmental variables based on correlation analysis and knowledge of interactions between soil salt and environmental variables were tested to predict total salt spatial variation using the similarity-based mapping method presented above. The evaluation results based on the validation points for total salt at $30-40 \mathrm{~cm}$ are listed in Table 4.

The first environmental datasets were built by choosing soil texture, the two distance indices and the highest-correlated variables from the terrain parameters, the temperature variables, NDVIs and the land surface reflectance data. The validation results for environmental dataset No. 1 were not acceptable. The spatial distribution of Dist_cl was found to be very similar to that of Ele (Fig. 1 and Fig. 2h), and the correlation between Dist_cl and Ele was nearly 0.9. Thus, the distance to the coastline information can be well represented by the elevation variable. Therefore, the Dist_cl variable was deleted and the results of dataset No. 2 were much better than those of dataset No. 1. Environmental dataset No. 3 in Table 4 was used to test the performance of the slope variable (Slp10), as it had the highest correlation coefficient among the terrain parameters except for elevation. However, adding Slp10 did not appear to improve the prediction accuracy. The comparison of results between environmental dataset No. 2 and No. 4 showed that soil texture played an important role when predicting soil salinity. The influencing factors and indicative factors were separated to predict soil salinity. It was shown that the indicative factors were as powerful as the influencing factors when predicting soil salinity at the $30-40 \mathrm{~cm}$ depth. The optimal combination of environmental variables was environmental dataset No. 2 in Table 4.

The predicted total salt map for the $30-40 \mathrm{~cm}$ depth based on environmental dataset No. 2 in Table 4 is shown in Fig. 4. It is shown that the closer to the Huanghe River, the lower total salt content, and the closer to the sea, the higher total salt content. The spatial distribution of soil total salt is influenced significantly

Table 2 Correlation coefficients between influencing variables and total salt

\begin{tabular}{|c|c|c|c|c|c|c|c|c|c|c|c|}
\hline Ele & Slp & Pcuv & Fcuv & Slp10 & Pcuv10 & Fcuv10 & TWI & Dist_cl & Dist_ic & T_avg_d & T_avg_n \\
\hline$-0.41^{* *}$ & -0.13 & -0.06 & -0.10 & -0.18 & -0.05 & -0.09 & -0.03 & $-0.32^{* *}$ & $0.21^{*}$ & $-0.25^{*}$ & $0.56^{* *}$ \\
\hline
\end{tabular}

Notes: *, **: correlation is significant at the 0.05 and 0.01 levels (2-tailed), respectively. Meanings of all the abbreviations mentioned in the table are listed in Table 1

Table 3 Correlation coefficients between indicative variables and total salt

\begin{tabular}{cccccccc}
\hline NDVI 031026 & NDVI 030924 & NDVI 030212 & NDVI 030127 & Lsr_b1 & Lsr_b2 & Lsr_b3 & Lsr_b4 \\
\hline$-0.45^{* *}$ & $-0.53^{* *}$ & $-0.30^{* *}$ & $-0.25^{*}$ & $0.26^{*}$ & 0.12 & 0.15 & $-0.36^{* *}$ \\
\hline Notes: ${ }^{*}, * *$ : correlation is significant at the 0.05 and 0.01 levels (2-tailed), respectively. Meanings of all the abbreviations mentioned in the table are listed in Table 1
\end{tabular}


Table 4 Validation results based on different environmental datasets for total salt at $30-40 \mathrm{~cm}$ depth

\begin{tabular}{|c|c|c|c|c|}
\hline No. & Environmental dataset & $\mathrm{CC}$ & MAE & RMSE \\
\hline 1 & ST, Ele, Dist_cl, Dist_ic, T_avg_n, NDVI030924, Lsr_b5 & 0.22 & 0.42 & 0.57 \\
\hline 2 & ST, Ele, Dist_ic, T_avg_n, NDVI030924, Lsr_b5 & 0.69 & 0.30 & 0.38 \\
\hline 3 & ST, Ele, Slp10, Dist_ic, T_avg_n, NDVI030924, Lsr_b5 & 0.69 & 0.30 & 0.38 \\
\hline 4 & Ele, Dist_ic, T_avg_n, NDVI030924, Lsr_b5 & 0.59 & 0.34 & 0.42 \\
\hline 5 & ST, Ele, Dist_ic,T_avg_n & 0.36 & 0.38 & 0.50 \\
\hline 6 & NDVI030924, Lsr_b5 & 0.41 & 0.38 & 0.54 \\
\hline
\end{tabular}

Notes: CC: correlation coefficient; MAE: mean absolute error; RMSE: root mean squared error. Meanings of other abbreviations mentioned in the table are listed in Table 1

by the input environmental variables (especially the remote sensing data and soil texture data) and reveals various degrees of details. Because the prediction was conducted for each soil texture type, there are abrupt variations along boundaries of some soil texture type polygons in Fig. 4. The scatter plot of the observed against predicted salt contents for the validation dataset is shown in Fig. 5. The plot also indicates that the accuracy of soil salt prediction is acceptable.

\section{Discussion}

The evaluation results showed that the similarity-based approach is powerful to predict soil salinity variations in the study area based on the selected environmental factors. The advantages of the similarity-based approach

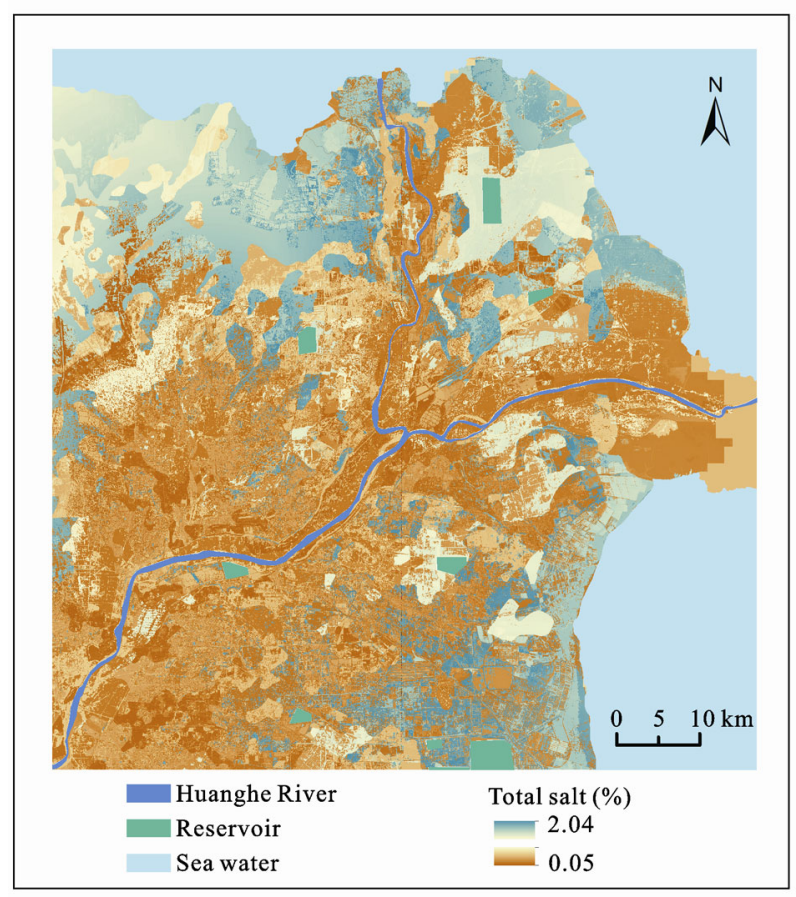

Fig. 4 Predicted total salt map of Huanghe River Delta using similarity-based predicting approach

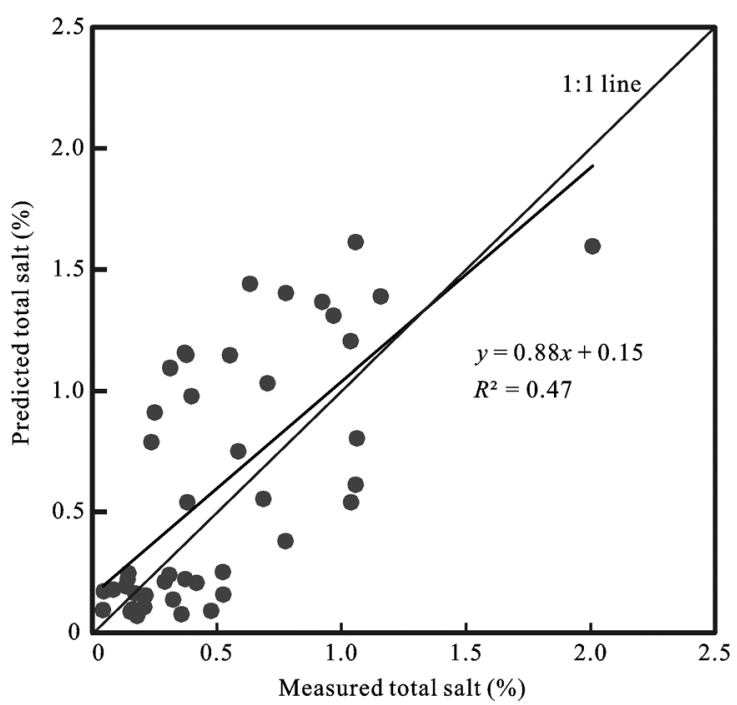

Fig. 5 Scatter plots of measured versus predicted total salt contents

are that it has no required number or distribution of sampled points and that it predicts the soil salinity values of each location based on the location's environmental similarities with the sampled locations rather than on a universal relationship. The degree of success of the similarity-based approach greatly depends on selection of environmental factors, representativeness of sampled points, and how the environmental similarities between unsampled locations and sampled locations are measured. The method used in this paper, which is based on the understanding of soil salinization mechanism and correlation analysis could be an effective way to select environmental factors. The evaluation results also showed that the strategies used to determine the environmental similarities in this study were acceptably effective. As for the sampled points, the better the sampled points could capture the relationships between soil salinity and its environment, the higher the accuracies of mapping results. Thus, representative sampling strategies such as an integrative hierarchical sampling strategy (Yang et al., 2013) are suggested for area with no 
observation data and requiring sampling.

The selection of suitable environmental variables is important, even more so than the selection of the prediction method (Sheng et al., 2010). Our results demonstrated that the choice of environmental variables does influence prediction accuracy. Except for that environmental variables should be selected according to knowledge of soil salinization mechanism in a study area, correlation analyses, such as those performed in this study, provide hints for selecting suitable environmental variables. The results showed that remote sensing data (the indicative variables) was very useful predictors for mapping soil salinization. The terrain attributes nearly did not work in our case study, because our study area is a flat plain. In our study, there are other variables such as, the table depth of the subsurface water, which are not available. This could affect the mapping results and accuracy. But these variables can be easily introduced into the similarity-based model when data are acquired.

In the predicted map, the eastern estuary area has low total salt contents, which is dissimilar to other areas along the coast. This difference is mainly because the eastern estuary area is greatly influenced by fresh water from the Huanghe River and is mostly used as agricultural land or for fish breeding. As shown in Fig. 1, there are few explanation points in the area, of which values of total salt are low, and one of the explanation points is near the Huanghe River. This finding may show that fresh water influences soil salinity in this area and may also influence the prediction results. Thus, more points are needed to obtain a better prediction for this area. The northern estuary area has relatively high total salt values in the predicted map, which is supported by the fact that the Huanghe River is often dry in this area.

Many studies have focused on predicting soil properties at different depths, and these models performed better for the soil surface than at depth (Minasny et al., 2006; Taghizadeh-Mehrjardi et al., 2014). TaghizadehMehrjardi et al. (2014) obtained $R^{2}$ value of 0.45 at depth of 30-60 cm, which is similar to our results, but $R^{2}$ value of 0.11 at depth of $60-100 \mathrm{~cm}$. It implies that our results are acceptable. The reason for the difference between results of surface and subsurface may be that the environmental variables (especially remote sensing data) are better able to capture surface variations than variations at depth, which is true for the variables used in the present study. More research using our methods on different depths should be done to examine the effect of our methods.

\section{Conclusions}

In this study, we investigated soil salinity variations in the Huanghe River Delta area using soil observation samples and environmental data combined with a similarity-based prediction approach. The main conclusions of this study are as follows. The similarity-based prediction approach combined with ancillary environmental data was a reliable approach to mapping spatial variations in soil salinity in the Huanghe River Delta area. Because high-resolution and high-precision DEMs and remote sensing data are increasingly available and easy to obtain, the similarity-based approach is likely to become a vital alternative to other mapping approaches. The elevation, distance to irrigation channels, soil texture, average night land surface temperature during the sampling period, NDVI on September 24, 2003, and land surface reflectance in Band 5 on October 26, 2003 are the optimal combination for the mapping of total soil salt at the 30-40 cm depth in the study area. This result was not only shown by these factors' correlation relationships with total salt but was also validated by the mapping accuracy results.

The main contribution of our study is that it demonstrates the potential predictive power of a similaritybased approach using environmental variables. Our findings are applicable to monitoring the spatial distribution of soil salinity and other resource mapping applications, particularly for precision agriculture and ecological studies. Future work will include predicting temporal soil salinity variations and how the locations and number of sampling points influence the prediction result.

\section{References}

Abbas A, Khan S, Hussain N et al., 2013. Characterizing soil salinity in irrigated agriculture using a remote sensing approach. Physics and Chemistry of the Earth, 55-57: 43-52. doi: 10.1016/j.pce.2010.12.004

Akramkhanov A, Martius C, Park S J et al., 2011. Environmental factors of spatial distribution of soil salinity on flat irrigated terrain. Geoderma, 163(1-2): 55-62. doi: 10.1016/j.geoderma. 2011.04.001

Cui B S, Tang N, Zhao X S et al., 2009. A management-oriented 
valuation method to determine ecological water requirement for wetlands in the Yellow River Delta of China. Journal for Nature Conservation, 17(3): 129-141. doi: 10.1016/j.jnc.2009. 01.003

Fan X, Pedroli B, Liu G H et al., 2012. Soil salinity development in the yellow river delta in relation to groundwater dynamics. Land Degradation and Development, 23(2): 175-189. doi: 10.1002/ldr.1071

Fang H L, Liu G H, Kearney M, 2005. Georelational analysis of soil type, soil salt content, landform, and land use in the Yellow River Delta, China. Environment Management, 35(1): 72-83. doi: 10.1007/s00267-004-3066-2

Farifteh J, Farshad A, George R J, 2006. Assessing salt-affected soils using remote sensing, solute modelling, and geophysics. Geoderma, 130(3-4): 191-206. doi: 10.1016/j.geoderma.2005. 02.003

Ghassemi F, Jakerman A J, Nix H A, 1995. Salinization of Land Water Resources. Wallingford: CAB International.

Gower J C, 1971. A general coefficient of similarity and some of its properties. Biometrics, 27(4): 857-871. doi: 10.2307/ 2528823

Hengl T, Heuvelink G B M, Rossiter D G, 2007. About regression-kriging: from equations to case studies. Computers \& Geosciences, 33(10): 1301-1315. doi: 10.1016/j.cageo.2007. 05.001

Jafari A, Finke P A, de Wauw J V et al., 2012. Spatial prediction of USDA-great soil groups in the arid Zarand region, Iran: comparing logistic regression approaches to predict diagnostic horizons and soil types. European Journal of Soil Science, 63(2): 284-298. doi: 10.1111/j.1365-2389.2012.01425.x

Li S N, Wang G X, Deng W et al., 2009. Influence of hydrology process on wetland landscape pattern: a case study in the Yellow River Delta. Ecological Engineering, 35(12): 1719-1726. doi: 10.1016/j.ecoleng.2009.07.009

Liu Jing, 2010. Mapping Soil Properties Using Individual Representativeness of Samples over Large Area. Beijing: Beijing Normal University. (in Chinese)

Ma Yulei, Wang De, Liu Junmin et al., 2013. Relationships between typical vegetations, soil salinity, and groundwater depth in the Yellow River Delta of China. Chinese Journal of Applied Ecology, 24(9): 2423-2430. (in Chinese)

Metternicht G I, Zinck J A, 2003. Remote sensing of soil salinity: potentials and constraints. Remote Sensing of Environment, 85(1): 1-20. doi: 10.1016/S0034-4257(02)00188-8

Minasny B, McBratney A B, Mendonca-Santos M L et al., 2006. Prediction and digital mapping of soil carbon storage in the Lower Namoi Valley. Australian Journal of Soil Research, 44(3): 233-244. doi: 10.1071/SR05136

Mougenot B, Pouget M, Epema G, 1993. Remote sensing of salt-affected soils. Remote Sensing Reviews, 7(3-4): 241-259. doi: 10.1080/02757259309532180

Qin C Z, Zhu A X, Pei T et al., 2007. An adaptive approach to selecting a flow-partition exponent for a multiple-flow-direction algorithm. International Journal of Geographical Information Science, 21(4): 443-458. doi: 10.1080/13658810601073240
Qin C Z, Lu Y J, Li B L et al., 2009. Simple digital terrain analysis software (SimDTA 1.0) and its application in fuzzy classification of slope positions. Journal of Geo-Information Science, 11(6): 737-743. (in Chinese)

Quinn P, Beven K J, Lamb R, 1995. The $\ln (\mathrm{a} / \mathrm{tanb})$ index: how to calculate it and how to use it within the TOPMODEL framework. Hydrological Processes, 9(2): 161-182. doi: 10.1002/ hyp.3360090204

Rodgers J L, Nicewander W A, 1988. Thirteen ways to look at the correlation coefficient. The American Statistician, 42(1): 59-66. doi: 10.1080/00031305.1988.10475524

Scull P, Franklin J, Chadwick O A, 2005. The application of classification of tree analysis to soil type prediction in a desert landscape. Ecological Modelling, 181(1): 1-15. doi: 10.1016/j. ecolmodel.2004.06.036

Sheng J D, Ma L C, Jiang P A et al., 2010. Digital soil mapping to enable classification of the salt-affected soils in desert agro-ecological zones. Agricultural Water Management, 97: 1944-1951. doi: 10.1016/j.agwat.2009.04.011

Shi X, Zhu A X, Burt J E et al., 2004. A case-based reasoning approach to fuzzy soil mapping. Soil Science Society of America Journal, 68(3): 885-894. doi: 10.2136/sssaj2004. 8850

Song Chuangye, Huang Chong, Liu Huimin, 2013. Predictive vegetation mapping approach based on spectral data, DEM and generalized additive models. Chinese Geographical Science, 23(3): 331-343. doi: 10.1007/s11769-013-0590-0

Taghizadeh-Mehrjardi R, Minasny B, Sarmadian F et al., 2014. Digital mapping of soil salinity in Ardakan region, central Iran. Geoderma, 213: 15-28. doi: 10.1016/j.geoderma.2013. 07.020

Triantafilis J, Odeh I O A, Mcbratney A B, 2001. Five geostatistical models to predict soil salinity from electromagnetic induction data across irrigated cotton. Soil Science Society of America Journal, 65(3): 869-878. doi: 10.2136/sssaj2001. 653869x

Wang X G, Lian Y, Huang C et al., 2011. Environmental flows and its evaluation of restoration effect based on LEDESS model in Yellow River Delta wetlands. Mitigation and Adaptation Strategies for Global Change, 17(4): 357-367. doi: 10.1007/s11027-011-9330-x

Webster R, Oliver M A, 2001. Geostatistics for Environmental Science. Toronto, Canada: John Wiley and Sons, LTD.

Xie T, Liu X H, Sun T, 2011. The effects of groundwater table and flood irrigation strategies on soil water and salt dynamics and reed water use in the Yellow River Delta, China. Ecological Modelling, 222(2): 241-252. doi: 10.1016/j.ecolmodel. 2010.01.012

Xu Xuegong, 1997. An analysis on the land structure in the Yellow River Delta. Acta Geographical Sinica, 64(1): 18-26. (in Chinese)

Yang L, Zhu A X, Qi F et al., 2013. An integrative hierarchical stepwise sampling strategy and its application in digital soil mapping. International Journal of Geographical Information Science, 27(1): 1-23. doi: 10.1080/13658816.2012.658053 
Yao R J, Yang J S, 2010. Quantitative evaluation of soil salinity and its spatial distribution using electromagnetic induction method. Agricultural Water Management, 97(12): 1961-1970. doi: 10.1016/j.agwat.2010.02.001

Ye Q H, Liu G H, Tian G L, 2004. Geospatial-temporal analysis of land-use changes in the Yellow River Delta in the last 40 years. Science in China Series D Earth Sciences, 47(11): 1008-1024. doi: 10.1360/03yd0151

Zhang T T, Zeng S L, Gao Y et al., 2011. Assessing impact of land uses on land salinization in the Yellow River Delta, China using an integrated and spatial statistical model. Land Use Policy, 28(4): 857-866. doi: 10.1016/j.landusepol.2011.03.002

Zhao X S, Cui B S, Sun T et al., 2010. The relationship between the spatial distribution of vegetation and soil environmental factors in the tidal creek areas of the Yellow River Delta. Ecology and Environmental Sciences, 19(8): 1855-1861. (in Chinese)

Zhou W Z, Tian Y Z, Zhu L F, 2007. Land use/land cover change in Yellow River Delta China during fast development period. Conference on Remote Sensing and Modelling of Ecosystems for Sustainability IV, San Antonio, CA. doi: 10.1117/12. 734015

Zhu A X, 1997. A similarity model for representing soil spatial information. Geoderma, 77: 217-242. doi: 10.1016/S00167061(97)00023-2

Zhu A X, Band L E, 1994. A knowledge-based approach to data integration for soil mapping. Canadian Journal of Remote Sensing, 20: 408-418. doi: 10.1080/07038992.1994.10874583 